David Dickson reports on the growing strength of the antinuclear movement-and a shift in strategy at the Nuclear Regulatory Commission.

THE US anti-nuclear movement 1 received a major morale booster last week when the Nuclear Regulatory Commission ordered the indefinite suspension of construction work on a 2,300 MW nuclear power facility at Seabrook in New Hampshire.

In what opponents of the facility hailed as an "historic breakthrough", and the state governor labelled an "asinine decision", the NRC commissioners voted by two to one to suspend construction until adequate studies of alternative sites have been carried out.

The decision was essentially procedural rather than technical. It followed a ruling by an appeal court in Boston in February that the Environmental Protection Agency had followed incorrect procedures in giving its approval to a cooling system which would discharge heated water into the sea (thus, according to critics, posing a threat to local marine life). In addition the NRC's Atomic Licensing and Safety Appeal Board ruled in April that not enough thought had been given to alternative sites for the power station, given that the choice of cooling systems was still open.

The EPA is holding new hearings into the proposed cooling scheme. The decision that faced the NRC commissioners was whether, in the light of these hearings and the appeal board ruling, construction should continue while the matters remain unresolved. Two of the three commissionersphysicist Victor Gilinsky and lawyer Peter Bradford-decided that, in view of the uncertainties, the suspension of work was justified.

The decision will mean that almost 2,000 workers will be laid off by the Public Service Co. of New Hampshire which began construction of the $\$ 2.3$ billion facility in 1976, and says that it is now $10 \%$ complete.

The two commissioners stated that the lay-offs were "the factor which weighed most strongly against suspension". However, they added: "We can only say that the opposite course would cause greater harm through failure to comply with the law and would risk the same impact on the workers through a court-imposed injunction in the immediate future."

The NRC's decision was announced at the end of a week which had seen a four-day rally attended by many thousands of protesters at the construction site in New Hampshire, and a subsequeent three-day demon-

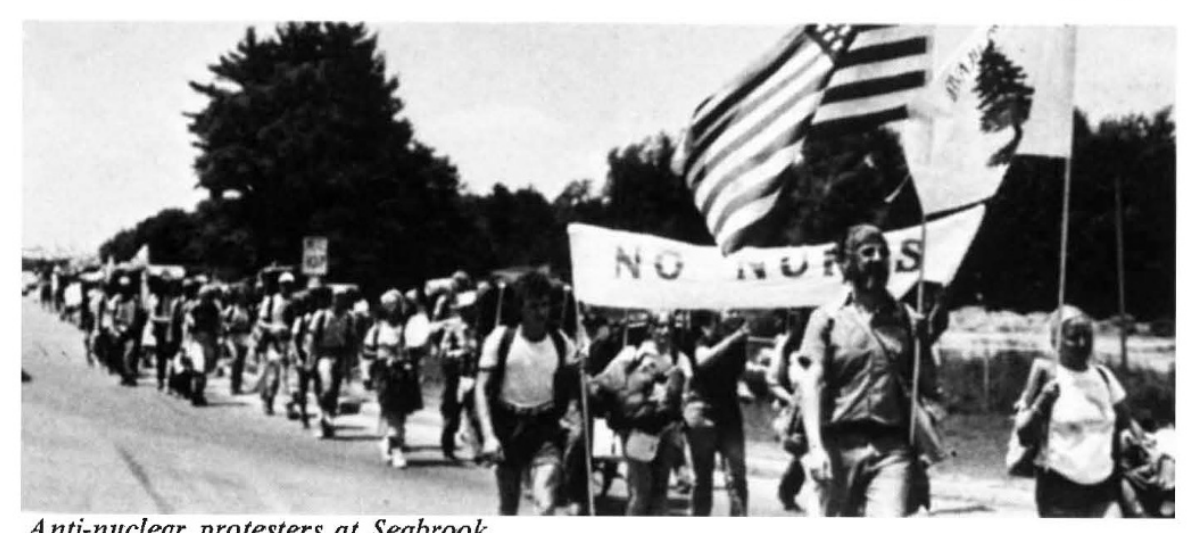

Anti-nuclear protesters at Seabrook

\title{
US regulators tread more warily on nuclear power
}

stration outside the NRC's offices in Washington by 100 members of a group called the Seabrook Natural Guard.

The decision itself came as a surprise to many of the demonstrators, who distrusted the NRC on the basis of previous pro-industry decisions. It was only after considerable debate within the Clamshell Alliance, a NewEngland-based collection of 53 groups which has been coordinating the Seabrook protest, that the decision to stage a Washington demonstration was made at all.

One effect has been a psychological boost for the anti-nuclear movement, which has been slowly gathering strength over the past few years, and whose conscious commitment to civil disobedience is reminiscent of the UK's Campaign for Nuclear Disarmament in the early 1960s. Following demonstrations at Seabrook over a number of years, with 180 people arrested in August 1976 and 1,415 during an occupation of the site in May 1977 , similar organisations have spring up across the country in opposition to local nuclear installations.

Seabrook, however, has remained the centre of attention. During the New Hampshire demonstrations, many of the other groups held supporting rallies. And although so far there has been a reluctance to bring grass-roots movements to Washington, a number of environmentalists feel that major demonstrations in the nation's capital may now become more common.

It is difficult to tell whether the demonstrations had much direct influence on the NRC's decision to suspend construction at Seabrook. But pressure from environmentalist groups has certainly played a major part in bringing decision-making into the open.

The NRC has become increasingly sensitive to criticism from both the public and Congress so that, despite its institutional separation from the Atomic Energy Authority in 1975, it has continued to reflect a desire to protect the nuclear industry.

Mr Russell Peterson, director of Congress' Office of Technology Assessment, expressed such concerns when he said recently that postwar strategies to develop civilian nuclear power had been "seriously flawed", and that inadequate efforts to insure the safety of nuclear power meant that "rather than enjoying wide public confidence, it has become highly controversial",

In recent months, both the commissioners and NRC staff members have been attempting to change their traditional image, recognising that, as commissioner Bradford commented on the Seabrook decision, "the courts, the legislative bodies, and the public are unlikely to tolerate nuclear expansion unless the regulators take the laws and their duties seriously".

Many have interpreted the Seabrook decision as a step in the right direction. In the past, for example, the NRC went to great lengths to keep a facility from shutting down. "Now at least it seems as if the commission is leaning over backwards to be procedurally fair," says Professor Frank von Hippel of the Centre for Environmental Studies at Princeton University.
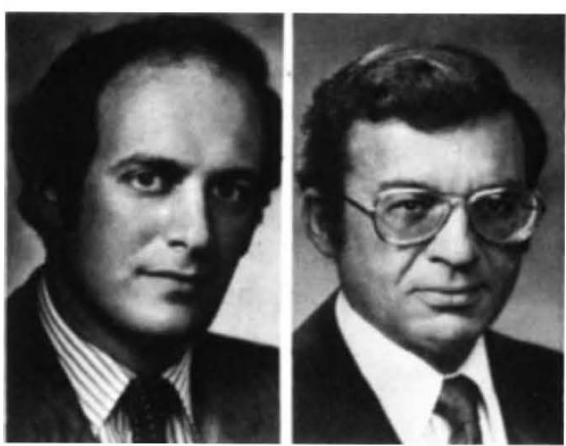

Commissioners Bradford and Gilinsky 
Further evidence that the NRC is pursuing a more independent role than in the past is reflected by the increasing criticism-previously reserved for agencies such as the Occupational Safety and Health Administrationthat it is beginning to attract. Following the Seabrook decision, for example, Congressional representatives from New Hampshire called for legal action to reverse the ruling. They want to amend the Department of Energy and the NRC appropriations bills to assure construction of the plant.

It would be wrong to interpret last week's decision as indicating any major weakening in the administration's support of nuclear power. A number of other recent decisions--such as the Supreme Court's ruling that the PriceAnderson Act, which limits public liability for nuclear accidents to $\$ 500$ million, is not unconstitutional-have not helped the anti-nuclear cause.

Furthermore even minor victories can have their price. Last week, a number of staff members responsible for a Congressional report critical of the way that subsidies had distorted the apparent costs of nuclear power were fired from their posts.

Yet whether or not the NRC allows the Seabrook plant to go ahead, both sides now recognise that nuclear power has become a political issue, with many wider issues at stake than merely the well-being of a few shell-fish-or the adequacy with which government regulators fulfil their functions.

During the Seabrook demonstration, for example, Dr John Goffman, for many years a critic of the health dangers of nuclear energy, told the rally that "nuclear power is a symptom of a societal disease, the existence of privilege and power", a theme echoed in many other speeches.

Equally Governor Meldrim Thomson of New Hampshire has vowed to make Seabrook the rallying cry of a pronuclear, grass-roots movement; while a research fellow from Harvard University, criticising the protesters in a letter to the New York Times, complained that "to protest nuclear power is to strike at the marriage of science and capitalism".

As far as Seabrook itself is concerned, the ball now rests with EPA administrator Doug Costle, to whom environmentalists are pressing their case as he decides whether to give the planned cooling system the go-ahead.

As to the broader issues, with regulatory action now making a major economic impact on the nuclear power industry and the NRC taking an increasingly indcpendent line, the struggle between the supporters and the opponents of nuclear power seems destined to grow more intense.

\section{Lack of basic energy research criticised}

THE long-range security of US energy supplies has been jeopardised by the failure of the Department of Energy to give sufficient attention to longrange, fundamental research, according to a study commissioned by the Office of Science and Technology Policy.

The working party which carried out the study recommends that the balance between short-term and long-term needs in the department's research programmes "should receive early attention at the highest levels".

The working party also says there is a lack of balance in the research programmes carried out on federal funds by DoE laboratories, industry and the universities. To redress the balance, it suggests the budget for basic energy research in the universities should be increased. If necessary "funds should be diverted for this purpose from the development activities or even from other parts of the basic research programme".

The study was commissioned by $\mathrm{Dr}$ Frank Press, director of OSTP, in December 1977, and was carried out by a working party that included representatives of industry, government and the academic community, chaired by Dr S. J. Buchsbaum of the Bell Telephone Laboratories.

In a scaled-down version of comments which OSTP has itself made of federal research efforts in general, the working party criticises a preoccupation with near-term programmes and the consequent neglect of longer-term work. The dearth of research is especially evident, it says, in the solar and fossil fuel programmes.

Among the reasons for this imbalance, the working party lists a "misguided emphasis" on goals given to, or adopted by, the department which are clearly not yet attainable, and "excessive sensitivity" of some programme managers to political pressures.

As a mechanism to correct this situation, it is suggested that a committee be established under the

\section{Decline in scientific knowledge among 17-year-olds}

THE science scores of 17 -year-olds in US schools has dropped by $4.7 \%$ since 1969, according to a report released in Washington by the National Assessment of Education Progress.

A study of 9-year-olds and 13-yearolds showed less of a decline and an improvement in somc areas. For example, both 9 and 13-year-old students improved in tests in the biological sciences.

However in all three age groups scores in the physical sciences were chairmanship of the director of the Office of Energy Research, which should decide how to allocate funds to basic research.

Under this structure basic research would remain the responsibility of each assistant secretary, and a linkage therefore maintained between the research and its applications; however it would be less easy for a particular division to claim that it had increased its basic research activities merely by redefining existing programmes.

As far as federal laboratories with an applied research mission are concerned, the working party does not make any specific recommendation. But, picking its words carefully, it says that the "crispness of their missions has slowly eroded" in recent years, and that there exists a need for "greater quality control" over their basic research effort.

Turning to specific research needs and opportunities, the report lists a number of areas-including fossil fuels, fusion energy, and large scale solar power-in which it says longrange fundamental research should more frequently be given priority. As far as research in the environmental and life sciences related to energy matters is concerned, the report says it is essential for the DoE to avoid the "credibility problems" of its predecessor agencies. It therefore suggests that primary responsibility for basic research should be assumed by the director of the Office of Energy Research where the work is common to several energy technologies, and that the Assistant Secretary for the Environment should provide support for basic research relevant to environmental concerns in the technology area.

Although the report has no official status, it is said to have been well received both by Dr Press, and Energy Secretary Dr James Schlesinger. Its reception by both fiscal conservatives, and those Congressmen concerned with specific development projects, however, is less predictable.

David Dickson

lower in the 1976-77 school year than in either of the previous two examiniation periods in 1969-70 and 1972-73.

The declining performances of 17 year-olds seems closely related to the fact that the number of students taking science courses in high school has dropped-from about $18 \%$ in the late $1960 \mathrm{~s}$, when attention on space exploration heightened interest, to less than 10 per cent now. 